\title{
Endlich Android!
}

_ Zugegeben: Es hat etwas gedauert. Doch nun ist sie da: die physiopraxis-App für Android-Betriebssysteme! Nachdem unsere App für Apples iOS erfreulich gut gestartet ist und nicht nur von Ihnen als Abonnent, sondern auch von „Einzelheftkäufern" kräftig genutzt wird, haben wir unser Portfolio erweitert und sind damit nun für die überwiegende Zahl aller Tablet-PCund Smartphone-Nutzer mobil verfügbar.

- Wie Sie die App herunterladen können, erfahren Sie auf Seite 6. Für unsere Abonnenten sind die App und jede Ausgabe von physiopraxis völlig kostenlos. Wer noch kein Abo hat, kann die App umsonst herunterladen und in zwei komplette Ausgaben gratis hineinschnuppern.

- Ich wünsche Ihnen ganz viel Spaß mit „physiopraxis to go" und freue mich auf Ihr Feedback.

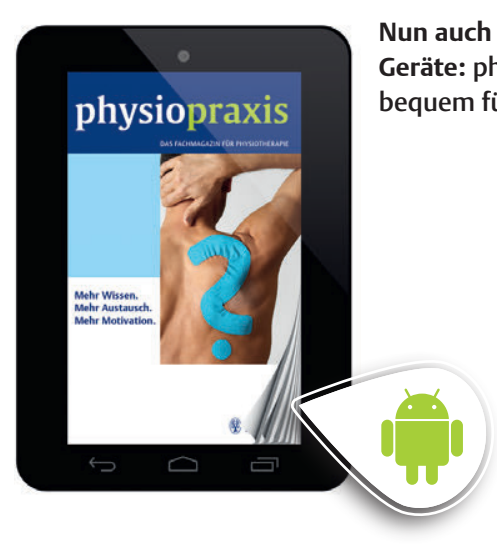

Herzlichst

Ihr

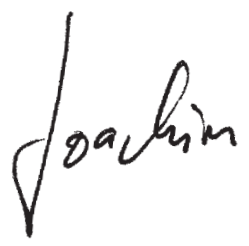<smiles>CCCCCCCCCCCCCC</smiles> 